\title{
Desempenho de Seis Gramíneas Solteiras ou Consorciadas com o Stylosanthes guianensis cv. Mineirão e Eucalipto em Sistema Silvipastoril
}

\section{Carlos Mauricio Soares de Andrade1, Rasmo Garcia², Laércio Couto ${ }^{3}$, Odilon Gomes Pereira ${ }^{4}$, Alexandre Lima de Souza ${ }^{5}$}

\begin{abstract}
RESUMO - Conduziu-se este estudo na região dos Cerrados de Minas Gerais, visando avaliar o desempenho de seis gramíneas forrageiras (Brachiaria brizantha cv. Marandu, B. brizantha cv. MG-4, B. decumbens cv. Basilisk, Panicum maximum cv. Mombaça, Melinis minutiflora e Hyparrhenia rufa), consorciadas ou não com a leguminosa Stylosanthes guianensis cv. Mineirão e Eucalyptus sp., em um sistema silvipastoril. As forrageiras foram estabelecidas em parcelas medindo 12 x $10 \mathrm{~m}$, nas entrelinhas do eucalipto, em um delineamento experimental de blocos ao acaso, com três repetições, e avaliadas quanto ao grau de cobertura do solo, \% de leguminosa e disponibilidade de matéria seca total no sub-bosque, um ano após o estabelecimento, submetidas a pastejos de curta duração. Após dois ciclos de pastejo, houve redução da proporção da leguminosa no consórcio com todas as gramíneas, sendo mais evidente com as mais agressivas (B. brizantha cv. Marandu e B. decumbens), onde ela quase desapareceu. Entretanto, a presença do estilosantes Mineirão favoreceu a produtividade do sub-bosque, quando consorciado com as demais gramíneas. O melhor desempenho produtivo foi obtido pelas gramíneas $B$. brizantha cv. Marandu, B. decumbens e $P$. maximum cv. Mombaça; a última principalmente quando consorciada com o estilosantes Mineirão.
\end{abstract}

Palavras-chave: consórcio, leguminosa, pastejo, persistência, sistemas agroflorestais, sombreamento

\section{Performance of Six Tropical Grasses Alone or Associated with Stylosanthes guianensis cv. Mineirão and Eucalypt in Silvopastoral System}

\begin{abstract}
A study was conducted in the Brazilian Cerrados to evaluate the performance of six tropical forage grasses (Brachiaria brizantha cv. Marandu, B. brizantha cv. MG-4, B. decumbens cv. Basilisk, Panicum maximum cv. Mombaça, Melinis minutiflora and Hyparrhenia rufa), associated or not with the tropical forage legume Stylosanthes guianensis cv. Mineirão, in a silvopastoral system with a clone of Eucalyptus sp. The forages were established in plots of $12 \times 10 \mathrm{~m}$, in the interrows of eucalypts, in a randomized block design with three replications. Ground cover, proportion of the legume and total dry matter availability in the understorey were evaluated one year after the establishment, under short time grazing. After two grazing cycles, there was reduction of the proportion of the legume in the mixture with all grasses, notably with the more aggressive ones (B. brizantha cv. Marandu and B. decumbens), where it practically disappeared. With the other grasses, however, the presence of the legume favored the productivity of the understorey. The grasses with the best productive performance were B. brizantha cv. Marandu, B. decumbens and P. maximum cv. Mombaça, the latter mainly when associated with the legume.
\end{abstract}

Key Words: agroforestry systems, grazing, legume, mixture, persistence, shading

\section{Introdução}

Os sistemas silvipastoris representam uma modalidade de uso da terra cuja exploração é bem mais complexa que a de pastagens cultivadas ou de florestas plantadas. A necessidade de manutenção do equilíbrio entre seus componentes (árvores, forrageiras e herbívoros), aliada ao grande número de interações possíveis entre estes e os fatores clima e solo, aumenta a necessidade de um planejamento rigoroso, incluindo mercado, produtos, espécies, arranjo e manejo, bem como as dificuldades gerenciais na condução da atividade. Atualmente, o maior entrave à exploração de sistemas silvipastoris sustentáveis está na falta de informações técnicas para auxiliar, tanto no planejamento quanto no gerenciamento de tais sistemas.

Um requisito fundamental para o sucesso de sistemas silvipastoris sustentáveis é a escolha acertada das espécies componentes do sistema. No caso das espécies forrageiras, não basta que estas sejam

\footnotetext{
1 Pesquisador da Embrapa Acre. Caixa Postal 321, CEP: 69908-970, Rio Branco, AC. E.mail: mauricio@cpafac.embrapa.br

2 Professor do Departamento de Zootecnia da UFV, bolsista do CNPq. E.mail: rgarcia@ufv.br

3 Professor do Departamento de Engenharia Florestal da UFV, bolsista do CNPq. E.mail: Icouto@ufv.br

4 Professor do Departamento de Zootecnia da UFV, bolsista do CNPq. E.mail: odilon@ufv.br

5 Doutor em Zootecnia/UFV. E.mail: alex-Is@bol.com.br
} 
tolerantes ao sombreamento, é necessário selecionar espécies com boa capacidade produtiva, adaptadas ao manejo e ambientadas às condições edafoclimáticas da região onde serão implantadas. Isto é particularmente importante quando se trata do ecossistema Cerrados, com suas características peculiares de solos pobres e ácidos, e com uma estação seca prolongada e bem definida.

Devido à pouca quantidade de estudos recomendando as espécies forrageiras mais adequadas para compor o sub-bosque de sistemas silvipastoris na região dos Cerrados, empresas como a Companhia Mineira de Metais (CMM) têm testado, empiricamente, algumas espécies de gramíneas em seus sistemas silvipastoris com eucalipto. Na Fazenda Riacho da CMM, localizada no noroeste de Minas Gerais, por exemplo, a Brachiaria brizantha cv. Marandu foi o material que apresentou melhor desempenho, sendo atualmente o único utilizado. Entretanto, a utilização em larga escala de apenas uma espécie forrageira é uma situação indesejável, devido à possibilidade da ocorrência de alguma praga ou enfermidade vir a causar grandes prejuízos.

Outro requisito importante para assegurar a sustentabilidade de sistemas silvipastoris, notadamente para aqueles com menor diversidade de espécies, consiste na agregação de leguminosas para aumentar o aporte de nitrogênio ao ecossistema. O problema da redução da disponibilidade de nitrogênio no solo tem sido identificado em florestas plantadas de Eucalyptus (Binkley \& Giardina, 1997), em pastagens cultivadas não consorciadas com leguminosas (Myers \& Robbins, 1991) e, também, em sistemas silvipastoris compostos por espécies de Eucalyptus e por gramíneas forrageiras (Andrade et al., 2001). Na região dos Cerrados, a leguminosa forrageira atualmente mais recomendada para a formação de pastos consorciados é o Stylosanthes guianensis cv. Mineirão. De acordo com a Embrapa (1993), esta leguminosa apresenta excelente adaptação às condições edafoclimáticas da região. Embora alguns autores (Shelton et al., 1987) afirmem que esta espécie apresenta baixa tolerância ao sombreamento, poucos são os trabalhos que avaliaram seu desempenho em sistemas silvipastoris. Em um deles, Steel \& Humphreys (1974) avaliaram o crescimento das leguminosas Centrosema pubescens, Stylosanthes guianensis cv. Endeavour e Lotononis bainesii cv. Miles, sob coqueirais maduros, com aproximadamente 30 anos de idade e apresentando boa transmissão de luz (77 a
$80 \%$ ), em Bali, Indonésia. Oestilosantes foi a leguminosa que apresentou o melhor crescimento inicial, a maior cobertura do solo, e as maiores taxas de acúmulo de matéria seca e de nitrogênio. Com a cultivar Mineirão, originária do Estado de Minas Gerais (Embrapa, 1993), ainda não existem trabalhos avaliando o seu comportamento sob condições sombreadas.

Assim, procurando fornecer subsídios para a implantação de sistemas silvipastoris sustentáveis na região dos Cerrados, foi realizado o presente estudo objetivando avaliar o desempenho de seis gramíneas forrageiras, consorciadas ou não com a leguminosa Stylosanthes guianensis cv. Mineirão, em um sistema silvipastoril com eucalipto.

\section{Material e Métodos}

O estudo foi realizado na Fazenda Riacho pertencente à Companhia Mineira de Metais (CMM), empresa do grupo Votorantim - localizada no município de Paracatu, Minas Gerais. A região está contida no grande bioma Cerrado, e situada à latitude $17^{\circ} 13^{\prime} \mathrm{S}$, longitude $46^{\circ} 52^{\prime} \mathrm{W}$ e altitude de $650 \mathrm{~m}$. As principais características climáticas do local são apresentadas na Figura 1.

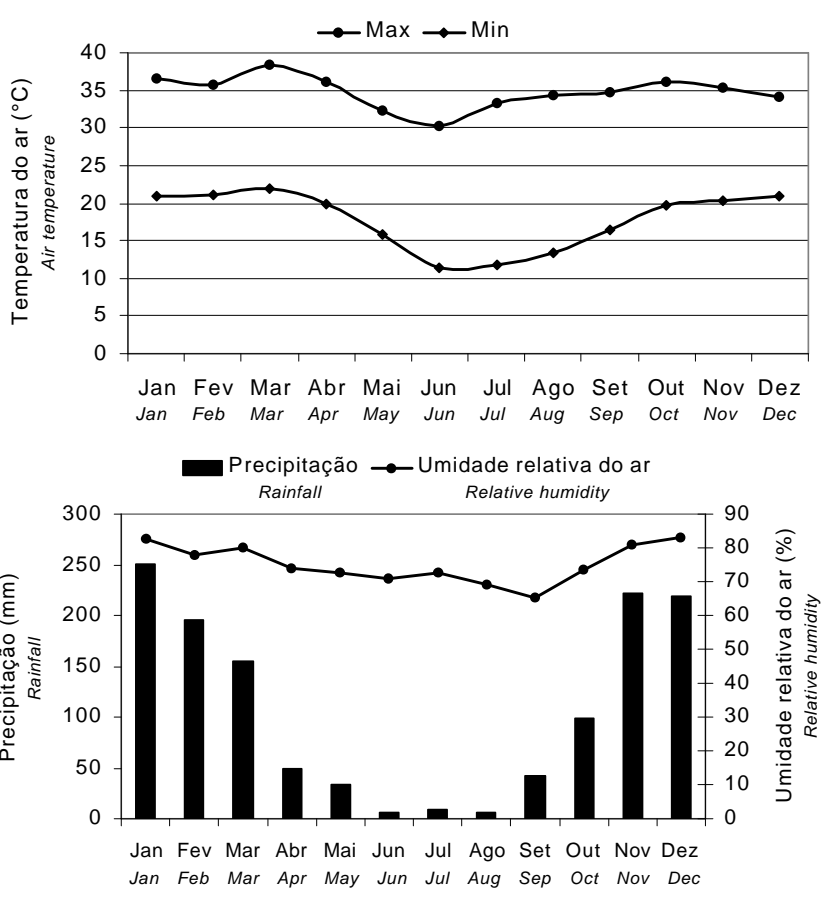

Figura 1 - Médias de dados climáticos da Fazenda Riacho, no período de 1988 a 1997, em Paracatu, MG.

Figure 1 - Means of the climatic data of the Riacho Farm, from 1988 to 1997, in Paracatu, MG, Brazil. 
O experimento foi conduzido em um sistema silvipastoril,implantadoemnovembrode 1996, constituído de um clone de Eucalyptus sp. plantado no espaçamento de $10 \times 4 \mathrm{~m}$, com as linhas de plantio orientadas no sentido leste-oeste. No ano de implantação, cultivou-se arroz de sequeiro nas entrelinhas do eucalipto, no ano seguinte foi cultivada soja e, no terceiro ano, foram estabelecidas as espécies forrageiras.

O solo da área experimental, classificado como Latossolo Vermelho-Escuro distrófico, com textura muito argilosa, apresentava por ocasião da implantação das espécies forrageiras as seguintes características químicas, respectivamente, nas profundidades de 0 a 20 e 20 a $40 \mathrm{~cm}: \mathrm{pH}$ em $\mathrm{H}_{2} \mathrm{O}=5,5$ e 4,5; $\mathrm{P}$ $\left(\right.$ Mehlich-1) $=3,1$ e 1,6 mg $/ \mathrm{dm}^{3} ; \mathrm{K}($ Mehlich-1) $=75$ e $30 \mathrm{mg} / \mathrm{dm}^{3} ; \mathrm{Ca}^{2+}=2,4$ e $0,4 \mathrm{cmolc} / \mathrm{dm}^{3} ; \mathrm{Mg}^{2+}=1,5 \mathrm{e}$ $0,2 \mathrm{cmolc} / \mathrm{dm}^{3} ; \mathrm{Al}^{3+}=0,0 \mathrm{e} 0,8 \mathrm{cmolc} / \mathrm{dm}^{3} ; \mathrm{H}+\mathrm{Al}^{3+}=6,0$ e $6,7 \mathrm{cmolc} / \mathrm{dm}^{3} ; \mathrm{SB}=4,15$ e $0,71 \mathrm{cmolc} / \mathrm{dm}^{3} ; \mathrm{CTC}$ efetiva $=4,19$ e $1,51 \mathrm{cmolc} / \mathrm{dm}^{3} ; \mathrm{CTC}$ pH 7,0 $=10,22 \mathrm{e}$ $7,41 \mathrm{cmolc} / \mathrm{dm}^{3} ; \mathrm{V}=40,7$ e $9,6 \% ; \mathrm{m}=0,7$ e $52,9 \%$.

As espécies forrageiras foram implantadas em novembro de 1998, em uma área de 0,8 ha localizada a 40 metros da borda do sistema silvipastoril, em um delineamento experimental de blocos casualizados, com três repetições. Os 12 tratamentos foram constituídos por seis gramíneas (Brachiaria brizantha cv. Marandu, B. brizantha cv. MG-4, B. decumbens cv. Basilisk, Panicum maximum cv. Mombaça, Melinis minutiflora e Hyparrhenia rufa) consorciadas ou não com o Stylosanthes guianensis var. vulgaris cv. Mineirão. As parcelas experimentais, com 12 x 10 m, foram estabelecidas entre as fileiras de eucalipto.

$\mathrm{O}$ preparo da área para plantio consistiu da aplicação de $18 \mathrm{~kg} /$ ha de $\mathrm{P}_{2} \mathrm{O}_{5}$, na forma de superfosfato simples, mais $96 \mathrm{~kg} / \mathrm{ha}$ de $\mathrm{P}_{2} \mathrm{O}_{5}$, na forma de fosfato natural de Araxá, seguida da passagem de grade niveladora. O plantio das espécies forrageiras foi feito a lanço, seguido da passagem de grade leve fechada para enterrar as sementes. As taxas de semeadura utilizadas para as gramíneas foram as seguintes: espécies de Brachiaria, 4,0 e $3,0 \mathrm{~kg} / \mathrm{ha}$ de sementes puras viáveis (SPV); capimmombaça, 2,0 e 1,5 kg/ha de SPV; capim-jaraguá e capim-gordura, 3,0 e 2,2 kg/ha de SPV, respectivamente, para os tratamentos em monocultivo e em consórcio. A leguminosa foi semeada à taxa de 2,5 kg/ha de SPV, juntamente com as gramíneas.

Em março de 1999, 120 dias após o plantio das forrageiras, realizou-se um corte de uniformização das parcelas experimentais (15 a $20 \mathrm{~cm}$ de altura), visando o pleno estabelecimento das espécies, ao incentivar o perfilhamento das gramíneas e diminuir o sombreamento exercido por estas sobre a leguminosa, que teve estabelecimento mais lento.

A participação da leguminosa no sub-bosque do sistema foi avaliada em dezembro de 1999, um ano após a implantação do experimento, ocasião em que as árvores de eucalipto estavam com três anos de idade, altura total de $16,4 \pm 0,7 \mathrm{~m}$ e diâmetro à altura do peito (DAP) de 16,2 $\pm 0,7 \mathrm{~cm}$. Para isso, a área de cada parcela $(12 \times 10 \mathrm{~m})$ foi subdividida em três subáreas $(4 \times 10 \mathrm{~m})$, as quais foram avaliadas visualmente, por dois observadores, quanto à porcentagem de leguminosa no consórcio, com base na cobertura do solo. Após esta avaliação, toda a área experimental foi cercada e submetida ao pastejo por novilhos, durante 24 horas, com oferta de forragem estimada em $10 \%$ do peso vivo dos animais. Este procedimento foi repetido em fevereiro de 2000, com o objetivo de simular a utilização do sistema com pastejo rotacionado.

Em abril de 2000, 60 dias após o último pastejo, avaliou-se a disponibilidade de matéria seca (MS), a cobertura do solo e, novamente, a participação da leguminosa no sub-bosque. Para avaliação da disponibilidade de MS, fez-se uma amostragem sistematizada casualizada, que consistiu na tomada de três amostras por parcela, uma em cada subárea de $4 \mathrm{x}$ $10 \mathrm{~m}$, utilizando-se quadrado de madeira medindo $100 \times 100 \mathrm{~cm}$. A altura de corte foi de $20 \mathrm{~cm}$ acima do solo para o Panicum maximum cv. Mombaça e $15 \mathrm{~cm}$ para as demais gramíneas. As amostras foram pesadas e subamostradas para determinação do teor e disponibilidade de matéria seca. A avaliação da cobertura do solo foi feita de maneira semelhante à da porcentagem de leguminosa.

Uma inspeção visual da nodulação das plantas de estilosantes foi realizada, a campo, em março de 1999 e repetida em abril de 2000. Em ambas as ocasiões, foi constatada a presença de nódulos efetivos, em número razoável, em todas as plantas inspecionadas.

Os dados referentes à disponibilidade de MS e à $\%$ de leguminosa foram submetidos à análise de variância e as médias comparadas pelo teste de Duncan, a $5 \%$ de probabilidade. Os dados de $\%$ de leguminosa, referentes à avaliação de abril de 2000 , por não atenderem ao pressuposto de normalidade, foram submetidos à transformação angular antes de serem analisados. Todas as análises estatísticas foram realizadas utilizando-se o procedimento GLM do pacote estatístico SAS (Littell et al., 1991). 


\section{Resultados e Discussão}

\section{Grau de cobertura do solo}

Em sistemas silvipastoris, a existência de um subbosque proporcionando boa cobertura do solo é importante para garantir a eficiente interceptação da radiação incidente, bem como para reduzir a possibilidade de erosão e do aparecimento de plantas indesejáveis. Neste estudo, os sub-bosques constituídos por gramíneas do gênero Brachiaria, independentemente de estarem ou não consorciados com o estilosantes Mineirão, foram aqueles que proporcionaram os mais elevados níveis de cobertura do solo (86 a $95 \%$; Figura 2), fato esperado devido à maior agressividade destas gramíneas em relação às demais. Já os capins jaraguá ( $H$. rufa) e gordura (M. minutiflora) foram os que proporcionaram menor cobertura do solo (64 a 70\%), com o capim-mombaça (P. maximum), ocupando posiçãointermediária $(77$ a $80 \%)$.

\section{Desempenho da leguminosa}

Em dezembro de 1999, um ano após o plantio das forrageiras, a participação do estilosantes Mineirão no sub-bosque foi maior quando consorciado com os capins gordura e jaraguá, intermediária quando consorciada com o capim-mombaça e com a $B$. brizantha cv. MG-4, obtendo-se os piores resultados quando em consórcio com a $B$. decumbens e a $B$. brizantha

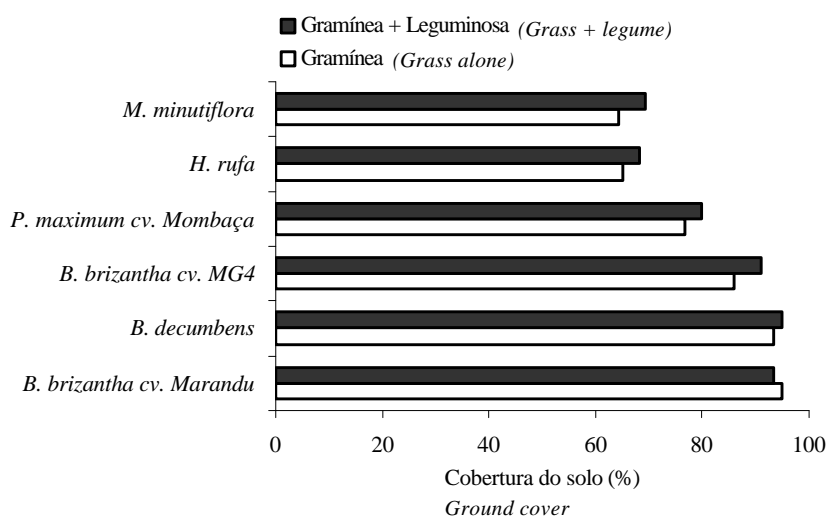

Figura 2 - Cobertura do solo de diferentes gramíneas, consorciadas ou não com o estilosantes Mineirão, no sub-bosque de um sistema silvipastoril, em abril de 2000, dois meses após pastejo por bovinos.

Figure 2 - Ground cover of different grasses, associated or not with Stylosanthes guianensis cv. Mineirão, in the understorey of a silvopastoral system, on April 2000, two months after grazing by beef steers. cv. Marandu, embora com diferenças nem sempre significativas estatisticamente (Tabela 1). Na avaliação feita em abril de 2000, após a realização de dois ciclos de pastejo na área, verificou-se que houve redução da participação da leguminosa em todos os tratamentos, principalmente naqueles com as gramíneas mais agressivas, onde o estilosantes Mineirão praticamente desapareceu.

Os resultados evidenciaram estreita relação entre a agressividade da gramínea associada, demonstrada pela capacidade de cobertura do solo, e a participação da leguminosa no sub-bosque do sistema. Os coeficientes de correlação entre porcentagem de cobertura do solo dos tratamentos não-consorciados e porcentagem de leguminosa no consórcio foram de $-0,93$ e $-0,95$, respectivamente, para a primeira e segunda avaliações. Portanto, quanto maior a agressividade da gramínea associada, menor a participação do estilosantes Mineirão no sub-bosque.

Alguns autores (Ludlow et al., 1974; Nelson, 1995) sugerem que, sob sombreamento, gramíneas e leguminosas forrageiras tropicais teriam igual capacidade competitiva, já que o nível ótimo de luz para as espécies $\mathrm{C}_{3}$ é inferior ao das $\mathrm{C}_{4}$. Os resultados do presente trabalho não confirmaram esta hipótese, já que após os dois ciclos de pastejo, houve redução da proporção da leguminosa em todos os tratamentos, estando de acordo com os resultados obtidos por Wong \& Wilson (1980), na Austrália, os quais constataram aumento da capacidade competitiva do P. maximum em relação à leguminosa Macroptilium atropurpureum cv. Siratro, sob sombreamento artificial. A proporção do siratro no consórcio, que era inicialmente de $40 \%$, foi reduzida para níveis tão baixos quanto 4 a $6 \%$, após 16 semanas, semelhante ao verificado para alguns consórcios no presente trabalho. Os autores também verificaram que a redução do intervalo de desfolhas de oito para quatro semanas favoreceu a gramínea no consórcio.

O manejo utilizado no presente trabalho - pastejos de curta duração ( $24 \mathrm{hs}$ ), com oferta de forragem de $10 \%$ do peso vivo, seguidos de período de descanso de 60 dias - favoreceu as gramíneas na competição com a leguminosa, apesar do longo período de descanso utilizado. Na realidade, a melhor forma de utilização do sub-bosque de sistemas silvipastoris ainda é um tema pouco estudado, seja ele composto apenas por gramíneas ou pelo consórcio de gramíneas com leguminosas. É necessário que sejam feitos mais estudos, utilizando leguminosas com diferentes hábi- 
Tabela 1 - Proporção do Stylosanthes guianensis cv. Mineirão no sub-bosque de um sistema silvipastoril, em função da gramínea associada

Table 1 - Proportion of Stylosanthes guianensis cv. Mineirão in the understorey of a silvopastoral system, as a function of the associated grass

Gramínea Participação da leguminosa ${ }^{\mathrm{a}}(\%)$

Grass

\begin{tabular}{lcc}
\cline { 2 - 3 } & $\begin{array}{c}\text { Dezembro } \\
\text { de } 1999\end{array}$ & $\begin{array}{c}\text { Abril de } \\
\text { December } \\
1999\end{array}$ \\
& 5000 \\
& April \\
Melinis minutiflora & $40,0^{\mathrm{a}}$ & 2000 \\
Hyparrhenia rufa & $35,0^{\mathrm{abc}}$ & $35,0^{\mathrm{a}}$ \\
Panicum maximum cv. & & $15,0^{\mathrm{a}}$ \\
Mombaça & & \\
Brachiaria brizantha cv. MG4 & $34,0^{\mathrm{bc}}$ & $13,0^{\mathrm{ab}}$ \\
Brachiaria decumbens & $21,7^{\mathrm{bc}}$ & $6,3^{\mathrm{b}}$ \\
Brachiaria brizantha $\mathrm{cv}$. & $18,3^{\mathrm{c}}$ & $2,3^{\mathrm{b}}$ \\
Marandu & &
\end{tabular}

a Médias seguidas pelas mesmas letras, nas colunas, não diferem $(P>0,05)$ pelo teste de Duncan.

${ }^{a}$ Means followed by the same letters, at the same column, are not different $(P>.05)$ by Duncan test.

tos de crescimento e graus de tolerância ao sombreamento, para maior entendimento do comportamento da associação de gramíneas e leguminosas forrageiras em sistemas silvipastoris.

Em abril de 2000, durante o levantamento da nodulação do Mineirão, foi constatado que algumas plantas apresentavam-se com coloração marrom, tombadas e com o coleto necrosado. Na ocasião não foi dada maior atenção à constatação, já que a ocorrência era relativamente baixa e os sintomas diferiam daqueles apresentados por plantas atacadas por antracnose, principal doença do gênero Stylosanthes, acreditando-se que o fato deveria ter sido causado por patógenos oportunistas que teriam infectado lesões provocadas pelo pisoteio dos bovinos. Entretanto, durante inspeção à área experimental, em junho de 2001, não foi possível encontrar nenhuma planta do estilosantes Mineirão, mesmo nas parcelas dos consórcios com os capins gordura e jaraguá, onde havia boa população de plantas por ocasião da última avaliação (Tabela 1). Cabe lembrar que no período compreendido entre abril de 2000 e a data desta inspeção, a área experimental foi mantida cercada e sem utilização. Esses fatos sugerem que alguma enfermidade teria sido responsável pelo desaparecimento do estilosantes Mineirão do sistema, provavelmente aquela constatada durante a última avaliação.

Kelemu et al. (1997) descreveram uma nova R. Bras. Zootec., v.32, n.6, p.1845-1850, 2003 (Supl. 2) doença, causada pelo fungo Lasiodiplodia theobromae, que vem alcançando proporções epidêmicas em campos de multiplicação de sementes, plantados com cultivares de $S$. guianensis resistentes à antracnose, no Brasil e na Colômbia. Os sintomas descritos são muito parecidos com os observados neste experimento. Além disso, os autores constataramque, dentre os oito genótipos de S. guianensis testados quanto à reação ao patógeno, a cultivar Mineirão foi a que apresentou maior susceptibilidade.

\section{Produção de forragem}

A B. brizantha $c v$. Marandu, a B. decumbens e o capim-mombaça, esse último especialmente quando consorciado com o estilosantes Mineirão, foram as gramíneas que apresentaram maior capacidade de produção de forragem nas condições impostas (Figura 3). Estes resultados estão de acordo com outros estudos realizados no Brasil (Carvalho et al., 1997; Castro et al., 1999; Andrade et al., 2002), os quais têm destacado o bom desempenho destas duas braquiárias e de várias cultivares de P. maximum, sob sombreamento.

A Brachiaria brizantha $\mathrm{cv}$. MG4 apresentou menor desempenho produtivo que as outras duas gramíneas do gênero. Já os capins-jaraguá e gordura foram as gramíneas que apresentaram mais baixa capacidade produtiva sob eucalipto, embora o capimjaraguá não tenha diferido estatisticamente $(\mathrm{P}>0,05)$ da B. brizantha cv. MG4 (Figura 3).

Com exceção dos consórcios com a $B$. brizantha cv. Marandu e a $B$. decumbens, em que a participação da leguminosa foi muito reduzida (Tabela 1), os demais consórcios apresentaram tendência de maior produção de forragem do que as respectivas gramíneas em monocultura (Figura 3). Esse resultado é importante, pois demonstra que a presença da leguminosa contribuiu para a produtividade do sub-bosque do sistema, apesar do curto período de tempo do consórcio.

Os resultados deste estudo permitem recomendar as gramíneas $B$. brizantha cv. Marandu, $B$. decumbens cv. Basilisk e P. maximum cv. Mombaça para compor o sub-bosque de sistemas silvipastoris na região dos Cerrados. Entretanto, algumas ressalvas devem ser feitas com relação às duas últimas gramíneas. Embora durante a condução do experimento não tenha ocorrido ataque de cigarrinha-das-pastagens na $B$. decumbens, provavelmente devido ao tamanho pequeno das parcelas e à diversidade de forrageiras na área experimental, não é recomendável a utilização em 


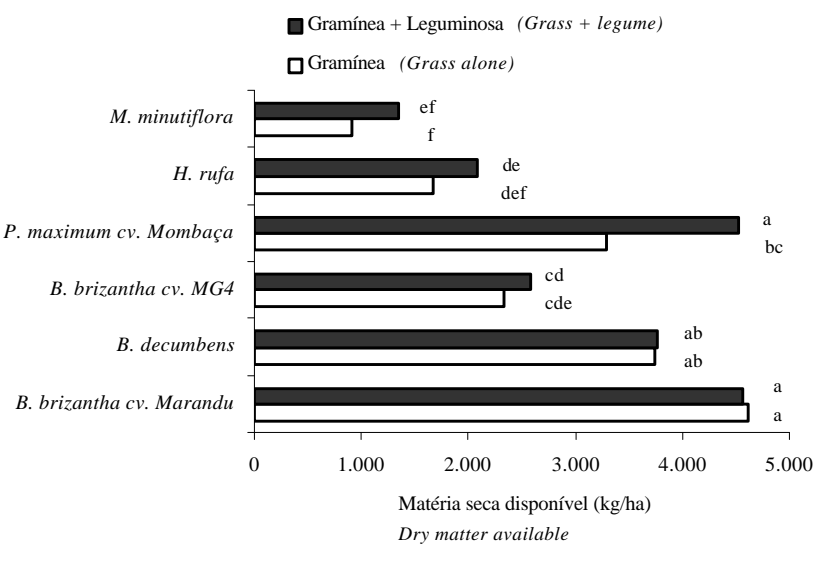

Figura 3 - Disponibilidade de matéria seca no sub-bosque de um sistema silvipastoril, em abril de 2000 , dois meses após pastejo por bovinos.

Figure 3 - Dry matter availability in the understorey of a silvopastoral system, on April 2000, two months after grazing by beef steers.

Médias seguidas pelas mesmas letras não diferem $(P>0,05)$ pelo teste de Duncan.

Means followed by the same letters are not different $(P>.05)$ by Duncan test.

monocultivo desta espécie em larga escala, devido à possibilidade de ataques severos desta praga. A utilização de mais de uma espécie forrageira, mesmo que em áreas separadas, é sempre uma opção inteligente para reduzir os riscos de problemas bióticos. No caso do P. maximum cv. Mombaça, sua utilização deve se restringir a áreas com solos de maior fertilidade, natural ou corrigida, de preferência sob lotação rotacionada.

\section{Conclusões}

As gramíneas $B$. brizantha cv. Marandu, $B$. decumbens cv. Basilisk e P. maximum cv. Mombaça apresentam boa capacidade produtiva, constituindo boas opções para compor sistemas silvipastoris na região dos Cerrados.

A consorciação com o Stylosanthes guianensis cv. Mineirão mostra-se inviável com as gramíneas do gênero Brachiaria e promissora como P. maximumcv. Mombaça.

\section{Agradecimento}

À Companhia Mineira de Metais (CMM), pela disponibilização da área experimental e pelo apoio financeiro, em especial ao Chefe Geral da Unidade Agroflorestal, Dr.Luciano Lage de Magalhães, e ao Gerente de Processos Pecuários, Dr. Arnaldo Geraldo Cardoso.

\section{Literatura Citada}

ANDRADE, C.M.S.; GARCIA, R.; COUTO, L. et al. Fatores limitantes ao crescimento do capim-tanzânia em um sistema agrossilvipastoril com eucalipto, na região dos Cerrados de Minas Gerais. Revista Brasileira de Zootecnia, v.30, n.4, p.1178-1185, 2001 (suplemento).

ANDRADE, C.M.S.; CARNEIRO, J.C.; VALENTIM, J.F. et al. Efeito do sombreamento sobre as taxas de acumulação de matéria seca de quatro gramíneas forrageiras. In: REUNIÃO ANUAL DA SOCIEDADE BRASILEIRA DE ZOOTECNIA, 39., 2002, Recife. Anais... Recife: Sociedade Brasileira de Zootecnia, 2002. 1 CD-ROM

BINKLEY, D.; GIARDINA, C. Nitrogen fixation in tropical forest plantations. In: NAMBIAR, E.K.S.; BROWN, A.G. (Eds.) Management of soil, nutrients and water in tropical plantation forests. Australia: ACIAR; CSIRO; CIFOR, 1997. p.297-337.

CARVALHO, M.M.; SILVA, J.L.O.; CAMPOS JR., B.A. Produção de matéria seca e composição química da forragem de seis gramíneas tropicais estabelecidas em um sub-bosque de angico vermelho. Revista Brasileira de Zootecnia, v.26, n.2, p.213-218, 1997.

CASTRO, C.R.T.; GARCIA, R.; CARVALHO, M.M. et al. Produção forrageira de gramíneas cultivadas sob luminosidade reduzida. Revista Brasileira de Zootecnia, v.28, n.5, p.919-927, 1999.

EMPRESA BRASILEIRA DE PESQUISA AGROPECUÁRIA - EMBRAPA. Recomendações para estabelecimento e utilização do Stylosanthes guianensis cv. Mineirão. Campo Grande: EMBRAPA-CNPGC, 1993. 6p. (Comunicado Técnico, 49).

KELEMU, S.; BADEL, J.L.; FERNANDES, C.D. A new dieback disease of the forage legume Stylosanthes guianensis in South America. Canadian Journal of Plant Pathology, v.19, p.376-379, 1997.

LITTELL, R.C.; FREUND, R.J.; SPECTOR, P.C.SAS ${ }^{\circledR}$ system for linear models. Cary: SAS Institute Inc., 1991. 329p.

LUDLOW, M.M.; WILSON, G.L.; HESLEHURST, M.R. Studies on the productivity of tropical pasture plants. V. Effect of shading on growth, photosynthesis and respiration in two grasses and two legumes. Australian Journal of Agricultural Research, v.25, p.425-433, 1974.

MYERS, R.J.K.; ROBBINS, G.B. Sustaining productive pastures in the tropics. 5. Maintaining productive sown grass pastures. Tropical Grasslands, v.25, p.104-110, 1991.

NELSON, C.J. Photosynthesis and carbon metabolism. In BARNES, R.F.; MILLER, D.A.; NELSON, C.J. (Eds.) Forages: an introduction to grassland agriculture. Ames: Iowa State University Press. 5.ed. 1995. v.1, p.31-43.

SHELTON, H.M.; HUMPHREYS, L.R.; BATELLO, C. Pastures in the plantations of Asia and the Pacific: performance e prospect. Tropical Grasslands, v.21, p.159-168, 1987.

STEEL, R.J.H.; HUMPHREYS, L.R. Growth and phosphorus response of some pasture legumes sown under coconuts in Bali. Tropical Grasslands, v.8, p.171-178, 1974.

WONG, C.C.; WILSON, J.R. Effects of shading on the growth and nitrogen content of green panic and siratro in pure and mixed swards defoliated at two frequencies. Australian Journal of Agricultural Research, v.31, p.269-285, 1980.

Recebido em: 12/07/02 Aceito em: $14 / 04 / 03$

R. Bras. Zootec., v.32, n.6, p.1845-1850, 2003 (Supl. 2) 